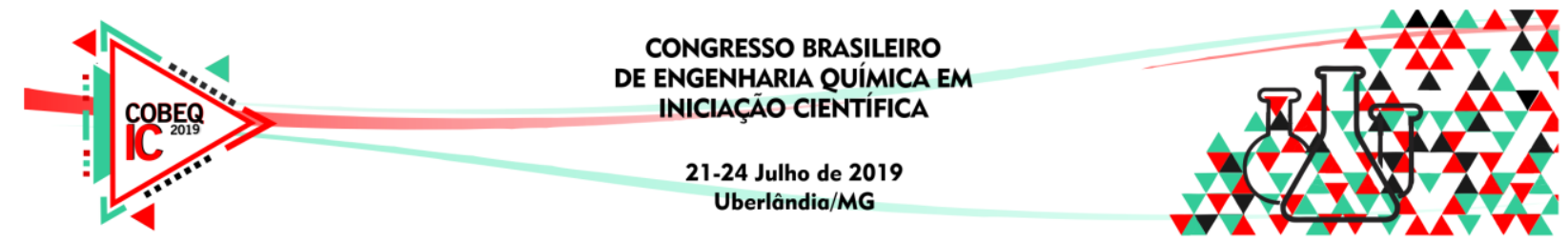

\title{
UTILIZAÇÃO DA VERMICULITA HIDROFÓBICA MODIFICADA COM ÓLEO DE MAMONA COMO POTENCIAL MATERIAL NA DESCONTAMINAÇÃO DE CURSOS D’ÁGUA
}

\author{
I. M. OLIVEIRA ${ }^{1}$, L. V. S. FRANCISCO ${ }^{1}$ e E. F. GUERRA ${ }^{1}$, V.D. CASTRO ${ }^{1}$ \\ ${ }^{1}$ Centro Universitário de Belo Horizonte \\ E-mail para contato: isabellamatos4@gmail.com
}

\begin{abstract}
RESUMO - A contaminação química da água vem crescendo exponencialmente a cada ano, advindo de indústrias têxteis, petrolíferas e de resíduos oleosos. Com as consequências dos efluentes líquidos, surge a cada dia a necessidade de um maior tratamento dos cursos d'água e, na busca por mecanismos capazes de descontaminar a água, a adsorção se mostra muito eficiente por permitir alta seletividade, recuperação e reutilização. A vermiculita é um mineral argiloso que, modificada, se torna eficiente na adsorção de materiais orgânicos, por apresentar propriedades como bom custo benefício, porosidade e elevados valores de área superficial específica. Tal modificação pode ser feita utilizando o óleo de mamona, por se tratar de um óleo de fácil acesso e de bom custo benefício. Dessa forma, o objetivo do trabalho envolve o teste da eficiência da vermiculita expandida e hidrofobizada com óleo de mamona. A comprovação de eficiência do material hidrofobizado, foi realizada através de testes de cinética e determinação da isoterma de adsorção, comparando-as aos modelos já existentes. As análises indicaram que a vermiculita exapandida e hidrofobizada com óleo de mamona apresentou uma adsorção de 99,56 \% do componente oleoso, sendo esta adsorção através do mecanismo de quimissorção em monocamada.
\end{abstract}

\section{INTRODUÇÃO}

Giordano (2004) descreve que a indústria utiliza uma grande quantidade de água em seus diversos processos industriais, em lavagem dos maquinários, tubulações e pisos, conjuntamente com a evaporação ou incorporação ao produto. Dessa forma, a água volta contaminada por rejeitos industrias aos seus corpos receptores, originando efluentes líquidos Schons (2008) relata que os poluentes mais prejudiciais ao meio ambiente são aqueles derivados do petróleo, uma vez que geram emulsões com a água, formando uma película insolúvel em sua superfície, impedindo assim trocas gasosas, penetração de luz e prejudicando processos de respiração e fotossíntese.

Oliveira (2015) ressalta que o processo mais utilizado para a descontaminação de lençóis freáticos e rios é o de adsorção, principalmente devido à utilização de adsorventes naturais, em que alguns são obtidos de subprodutos da indústria e da agricultura. Um dos materiais empregados é a vermiculita, um argilomineral que possui entre suas propriedades, elevados valores de área superficial específica, carga superficial negativa, porosidade e bom 


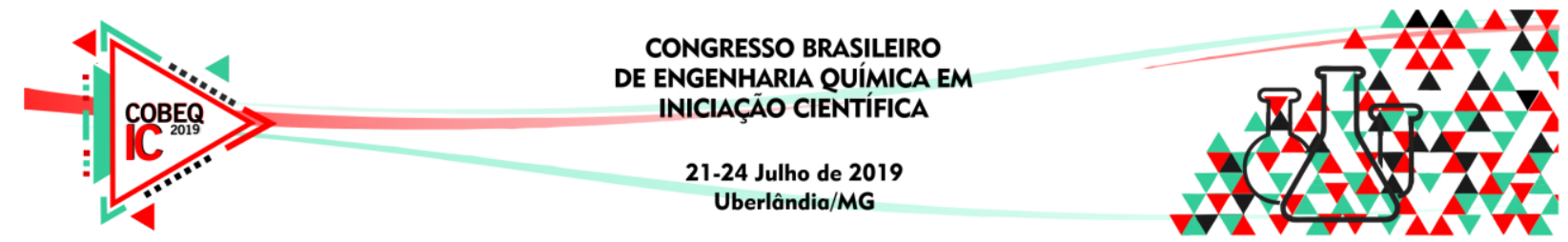

custo benefício como descrito por Urgate, Sampaio e França (2008). Sendo assim, a vermiculita é um material acessível e adequado para ser usado como adsorvente.

Por se tratar de uma argila hidrofílica deve-se realizar processos no material para que se torne seletivo aos derivados do petróleo. O método empregado é chamado de hidrofobização, que consiste na utilização de um agente orgânico dissolvido, com o objetivo de tornar o material seletivo a contaminantes de mesma origem química. Conforme Medeiros (2018) o óleo de mamona, se mostra um agente hidrofobizante interessante por possuir alta densidade, boa viscosidade e solubilidade em solventes de média polaridade.

Visto os problemas enfrentados, como a diminuição dos danos ambientais causados por contaminantes de origem petrolífera, surge a necessidade de retirá-los dos cursos d'água. A vermiculita hidrofobizada com óleo de mamona, demonstra ser um adsorvente potencial, na remoção de tais compostos.

\section{METODOLOGIA}

O preparo das amostras de vermiculita foi dividido em duas etapas, sendo seleção granulométrica e purificação das impurezas; expansão da área específica do material por lixiviação; e o processo de hidrofobização.

A amostra de vermiculita, passou por uma separação granulométrica, através de peneiras Serie Tyler, optou-se pela utilização de partículas de diâmetro médio de 2,0 mm nos demais testes e análises. Tal material foi lavado com água corrente para retirar as impurezas, secando na estufa à temperatura de $100^{\circ} \mathrm{C}$, por um período de $24 \mathrm{~h}$.

Com o objetivo de aumentar ainda mais a área superficial específica do material, foi realizado um processo de expansão, por meio da lixiviação das amostras com ácido clorídrico ( $\mathrm{HCl})$ 0,50 mol. $\mathrm{L}^{-1}$, na proporção de $10,0 \mathrm{~mL}$ de ácido por grama de vermiculita. O processo ocorre sob agitação constante e temperatura $80 \pm 5^{\circ} \mathrm{C}$, até a total evaporação do ácido. Para a neutralização da amostra, foram utilizados $250,0 \mathrm{~mL}$ de bicarbonato de sódio $\left(\mathrm{NaHCO}_{3}\right)$ 16.000,0 mg.L $\mathrm{L}^{-1}$, em contato por $10 \mathrm{~min}$. Após o período estipulado, a amostra é lavada com água destilada corrente, para retirada do excesso de solução e seca na estufa à temperatura de $100{ }^{\circ} \mathrm{C}$ durante $24 \mathrm{~h}$.

Após os procedimentos de lavagem e lixiviação realizou-se o processo de hidrofobilização com óleo de mamona, para que o material se tornasse seletivo ao contaminante (óleos e graxas), na proporção de $10 \%$ em relação à massa da amostra de vermiculita. Para melhor adequação e aderência ao material o óleo foi dissolvido em clorofórmio P.A na proporção de $1,57 \mathrm{~mL}$ do solvente para cada grama do material. As amostras foram deixadas em repouso na capela de exaustão até total evaporação do solvente.

Para atestar o poder adsortivo da amostra de vermiculita hidrofobizada com óleo de mamona, foram realizados testes de cinética de adsorção e criação da isoterma, conforme metodologias abaixo. 


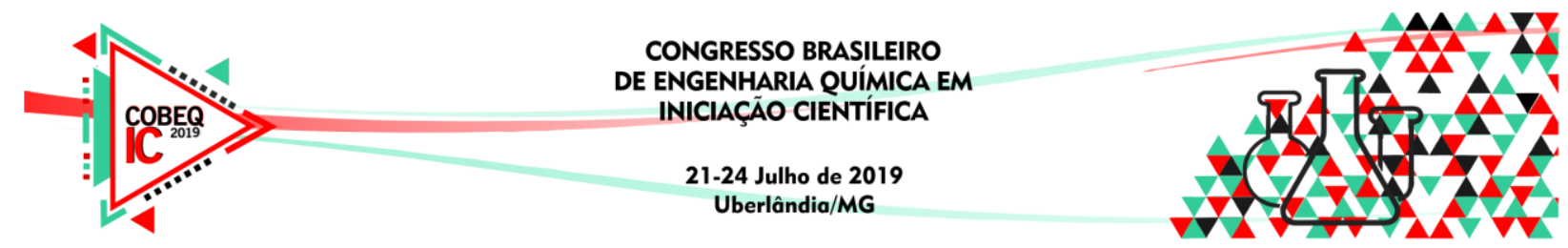

\subsection{Cinética de Adsorção}

Primeiramente foi elaborada uma curva de calibração contendo clorofórmio e óleo diesel, utilizando-se o espectrofotômetro UV/visível modelo UV-5100 da marca Global Trade Technology, com um comprimento de onda $244,500 \mathrm{~nm}$. O software utilizado foi o UV Basic V1 40.0.

Amostras contendo 0,10 g de vermiculita já hidrofobizada e 50,0 mL de emulsão óleo diesel e água (1.000 mg.L $\mathrm{L}^{-1}$ ) foram expostas à agitação mecânica em um shaker, marca Tecnal TE-424, durante um período total de $04 \mathrm{~h}$.

Submeteram-se as amostras ao processo de extração líquido-líquido, retirando duas alíquotas, de cada amostra, com $10 \mathrm{~mL}$ de clorofórmio P.A. que posteriormente foram transferidas para balões volumétricos de $25,0 \mathrm{~mL}$ completando o volume até o menisco com o solvente. Leituras no espectrofotômetro UV/vis foram realizadas a cada $30 \mathrm{~min}$, sobre a curva de calibração pré-estabelecida para quantificação da adsorção do óleo pelo material hidrofobizado.

\subsection{Isoterma de Adsorção}

A criação da isoterma tem como objetivo a comprovação do processo adsortivo e as interações entre adsorvente e o adsorbato, quando comparada às isotermas já prédeterminadas, como a de Langmuir e a de Freundlich, conforme Equação 1 e Equação 2, respectivamente.

$$
\begin{aligned}
& q=\frac{q_{\max } K_{L} C_{e}}{1+K_{L} C_{e}} \\
& q_{e}=K_{F} C_{e}^{1 / n}
\end{aligned}
$$

O processo consiste em adicionar $0,10 \mathrm{~g}$ de vermiculita expandida hidrofobizada em contato com 50,0 mL de emulsão óleo e água, em diferentes concentrações (variando de 500 a 16.000,0 mg. $\mathrm{L}^{-1}$ ). Quando o equilíbrio de adsorção é atingido, temos a concentração final do soluto na solução e a capacidade de adsorção do adsorvente

As amostras são expostas à temperatura ambiente e rotação de $120 \mathrm{rpm}$ no shaker, durante um intervalo de $04 \mathrm{~h}$. Após esse período, as amostras são filtradas e os líquidos resultantes são submetidos ao processo de extração líquido-líquido, como procedimento descrito no item 2.1, e lidos no espectrofotômetro UV/vis para obter as concentrações finais das substâncias de interesse.

\section{RESULTADOS E DISCUSSÕES}

A amostra de vermiculita utilizada nas demais análises e para comprovação do poder adsortivo, possui granulometria de $2,0 \mathrm{~mm}$. A mesma foi expandida utilizando-se $\mathrm{HCl}$ na concentração de 0,50 mol. $\mathrm{L}^{-1}$ e percentual de hidrofobização real de $9,8 \%$ de óleo em relação à massa da argila. 


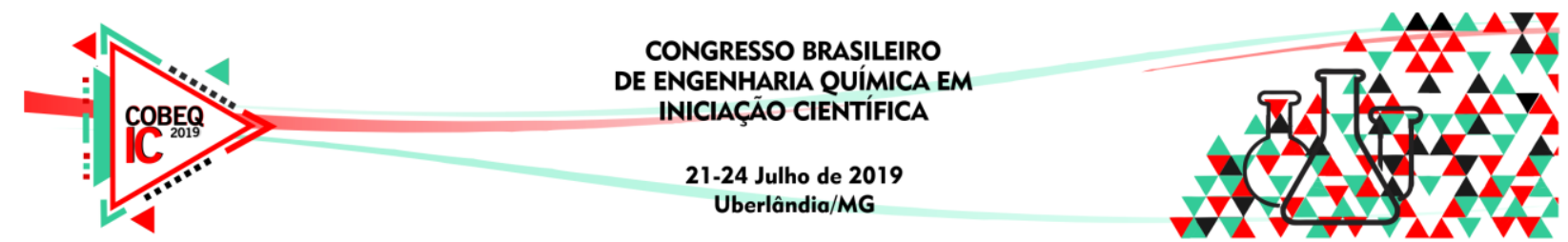

A partir dos resultados obtidos no teste de cinética, plotou-se o gráfico q $\left(\mathrm{mg} \mathrm{g}^{-1}\right)$ versus tempo (min), a partir da Equação 3. Notou-se que o material possui alto percentual de adsorção de óleos e graxas $(99,65 \%)$, como pode ser comprovado pelo Gráfico 1 .

$$
q=\frac{\left(C_{0}-C_{e}\right) v}{m}
$$

Gráfico 1 - Teste de cinética do material hidrofobizado com óleo de mamona

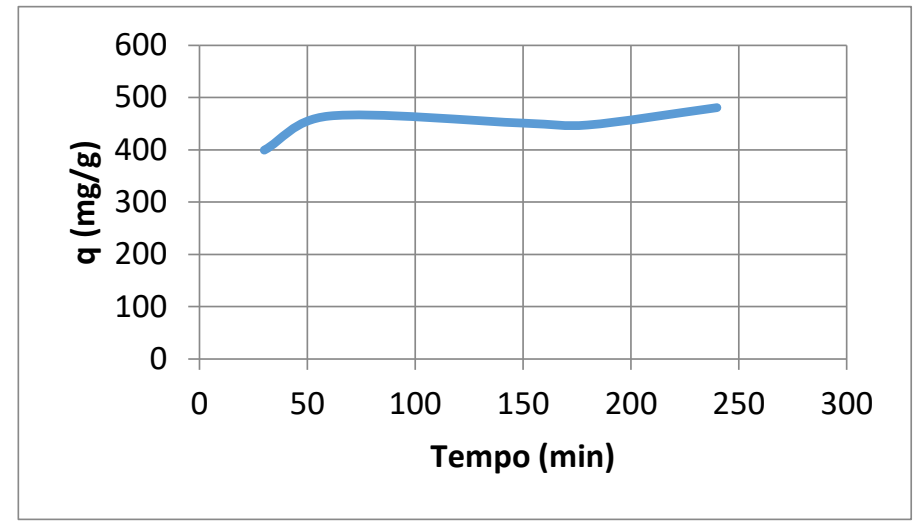

A partir disso, foram traçados gráficos para determinar a adequação aos modelos cinéticos já conhecidos de pseudoprimeira ordem e pseudosegunda ordem e definir os principais parâmetros e a linearidade, como observado nas Tabela 1.

Tabela 1 - Parâmetros do teste cinético comparando-o com os modelos de pseudoprimeira ordem e pseudosegunda ordem

\begin{tabular}{|c|c|c|c|c|c|}
\hline \multicolumn{3}{|c|}{ Pseudoprimeira ordem } & \multicolumn{3}{c|}{ Pseudosegunda ordem } \\
\hline $\mathrm{k}\left(\mathrm{min}^{-1}\right)$ & $\mathrm{q}_{\mathrm{e}}\left(\mathrm{mg} \cdot \mathrm{g}^{-1}\right)$ & $\mathrm{R}^{2}$ & $\mathrm{k}\left(\mathrm{g} \cdot \mathrm{mg}^{-1} \cdot \mathrm{min}^{-1}\right)$ & $\mathrm{q}_{\mathrm{e}}\left(\mathrm{mg} \cdot \mathrm{g}^{-1}\right)$ & $\mathrm{R}^{2}$ \\
\hline 0,0081 & 20,009 & 0,1435 & 0,000347 & 476,19 & 0,996 \\
\hline
\end{tabular}

Pôde-se observar uma maior adequação ao modelo cinético de pseudosegunda ordem, comprovando que a diferença entre a concentração da fase sólida em qualquer tempo é a força motriz da adsorção. A partir disso, segundo Bastos (2015) o mecanismo apresentado é a quimissorção, envolvendo ligações covalentes entre o adsorvato e o adsorvente, com alta especificidade e caracterizando uma adsorção mais forte.

Os resultados obtidos na isoterma de adsorção foram organizados plotando o gráfico q (mg. $\left.\mathrm{g}^{-1}\right)$ versus $\mathrm{Ce}(\mathrm{mg} / \mathrm{L})$, conforme observado no Gráfico 2. Observa-se uma adsorção significativa, com capacidade de adsorção de aproximadamente $7.000 \mathrm{mg} \cdot \mathrm{g}^{-1}$. 


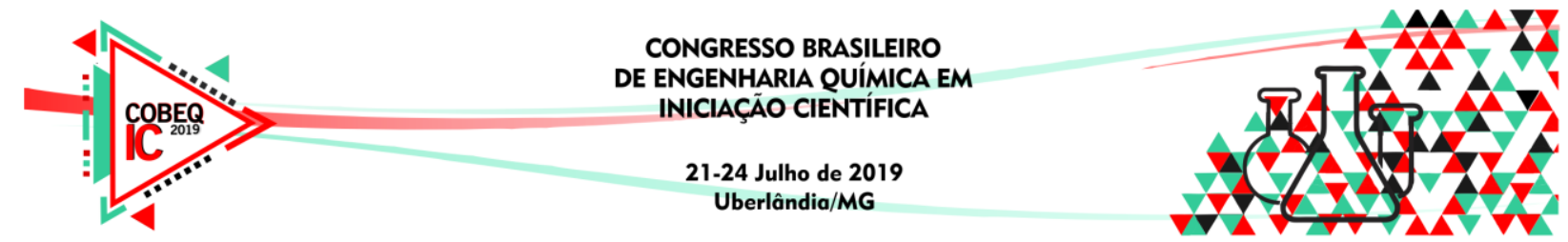

Gráfico 2 - Teste de isoterma de adsorção do material hidrofobizado com óleo de mamona

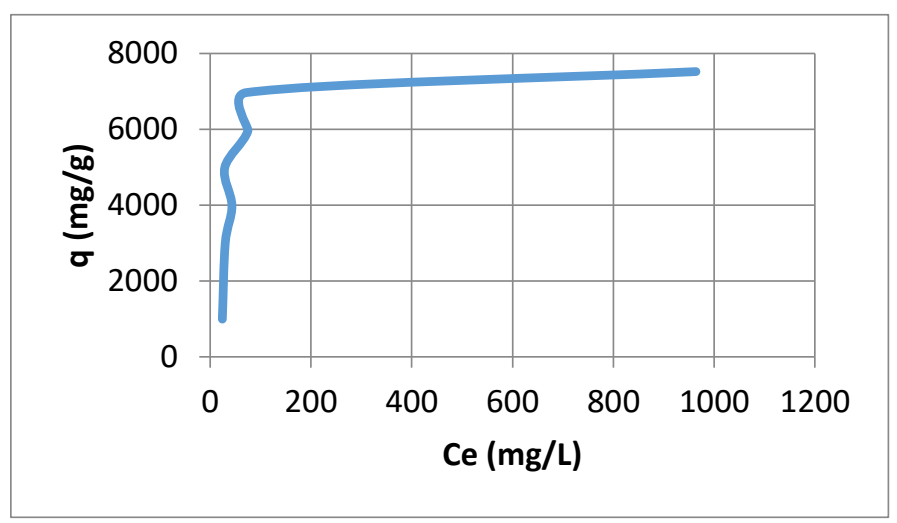

Em seguida os resultados foram avaliados segundo a Equação 4 e Equação 5, na forma linear dos modelos de Langmuir e Freundlich. Após foram relacionados a adequação aos modelos, segundo Tabela 2.

$$
\begin{aligned}
& \frac{q_{e}}{C_{e}}=K_{L} q_{\max }-K_{L} q_{e} \\
& \ln q_{e}=\ln K_{F}+\frac{1}{n} \ln C_{e}
\end{aligned}
$$

Tabela 2 - Parâmetros da isoterma de adsorção comparando-o com os modelos de Langmuir e Freundlich

\begin{tabular}{|c|c|c|c|c|c|}
\hline \multicolumn{3}{|c|}{ Isoterma de Langmuir } & \multicolumn{3}{c|}{ Isoterma de Freundlich } \\
\hline $\mathrm{q}_{\max }\left(\mathrm{mg} \cdot \mathrm{g}^{-1}\right)$ & $\mathrm{K}_{\mathrm{L}}\left(\mathrm{L} \cdot \mathrm{mg}^{-1}\right)$ & $\mathrm{R}^{2}$ & $\mathrm{n}$ & $\mathrm{K}_{\mathrm{F}}\left(\mathrm{mg}^{1-(1 / \mathrm{n})} \cdot \mathrm{g}^{-1} \cdot \mathrm{L}^{1 / \mathrm{n}}\right)$ & $\mathrm{R}^{2}$ \\
\hline 10000 & 0,015 & 0,9756 & 2,983 & 1003,14 & 0,368 \\
\hline
\end{tabular}

Um indicativo muito utilizado no modelo de Langmuir é o fator $\mathrm{R}_{\mathrm{L}}$ (fator de separação) que determina o quão favorável é a adsorção, conforme calculado na Equação 6. Observa-se um fator $\mathrm{R}_{\mathrm{L}}$ de 0,066, considerando, de acordo com Nascimento et al. (2014), a adsorção da vermiculita expandida hidrofobizada com óleo de mamona favorável $\left(\mathrm{R}_{\mathrm{L}}<1\right)$.

$$
R_{L}=\frac{1}{1+K_{L} C_{0}}
$$

Pôde-se observar uma maior adequação a isoterma de Langmuir, com uma capacidade máxima de adsorção de $10.000 \mathrm{mg} \cdot \mathrm{g}^{-1}$, comprovando uma adsorção em monocamada na superfície do adsorvente. Interpretando que, de acordo com Peruzzo (2003), cada molécula é adsorvida em sítios definidos, com energia de ativação igual, sendo que as moléculas não interagem entre si. 


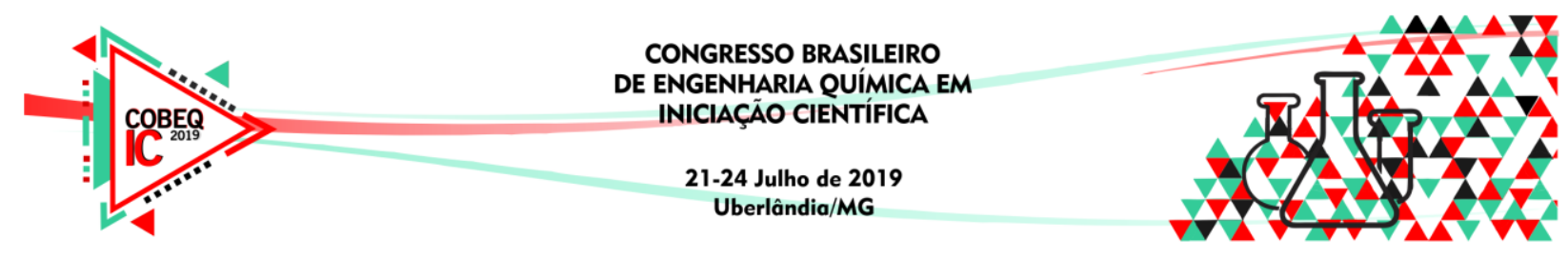

\section{CONCLUSÃO}

A vermiculita expandida e hidrofobizada com óleo de mamona, pode ser considerada um bom material adsorvente de óleos e graxas, visto que obteve-se um percentual de adsorção no âmbito de 99,56 \% do material em um prazo de $4 \mathrm{~h}$. Além disso, essa adsorção corresponde ao modelo quimissorção, formando ligações covalentes entre o adsorvente e o adsorvato, possibilitando maior estabilidade de adsorção. Outro fator relevante é a não interferência de moléculas do adsorvente em diferentes sítios ativos.

\section{NOMENCLATURA}

$\mathrm{C}_{0}$ : concentração inicial do adsrovato $\left(\mathrm{mg} . \mathrm{L}^{-1}\right) ; \mathrm{C}_{\mathrm{e}}$ : concentração no equilíbrio $\left(\mathrm{mg} . \mathrm{L}^{-1}\right)$; m: massa do adsorvente $(\mathrm{g})$; $\mathrm{q}_{\mathrm{e}}$ : capacidade de adsorção $\left(\mathrm{mg}_{\mathrm{g}} \mathrm{g}^{-1}\right)$; t: tempo (min); $\mathrm{k}_{1}$ : constante cinética de primeira ordem $\left(\mathrm{min}^{-1}\right) ; \mathrm{k}_{2}$ : constante cinética de segunda ordem $\left(\mathrm{g}^{\mathrm{m}} \mathrm{mg}^{-1} \cdot \mathrm{min}^{-1}\right)$; $\mathrm{q}_{\text {max }}$ : capacidade máxima de adsorção $\left(\mathrm{mg} \mathrm{g}^{-1}\right)$; $\mathrm{R}_{\mathrm{L}}$ : fator de separação; v: volume da solução (L); n: constante relacionada a heterogeneidade da superfície; $\mathrm{K}_{\mathrm{L}}$ : constante de capacidade de adsorção de Langmuir (L.mg $\left.{ }^{-1}\right)$; KF: constante de capacidade de adsorção de Freundlich $\left(\mathrm{mg}^{1-(1 / \mathrm{n})} \cdot \mathrm{g}^{-1} \cdot \mathrm{L}^{1 / \mathrm{n}}\right)$.

\section{REFERÊNCIAS}

BASTOS, Andréa de Castro. Adsorção de metais em solução aquosa pelos processos de batelada e coluna de leito fixo utilizando silsesquioxano funcionalizado com 5- amino1,3,4-tiadiazol-2-tiol. 2015. 144 f. Tese - Curso de Ciência dos Materiais, Faculdade de Engenharia, Universidade Estadual Paulista "Júlio de Mesquita Filho", Ilha Solteira, 2015 .

GIORDANO, Gandhi. Tratamento e controle de efluentes industriais. Revista ABES, 2004.

MEDEIROS, Everaldo Paulo. Óleo de Mamona.

NASCIMENTO, Ronaldo Ferreira do et al. Adsorção: Aspectos teóricos e aplicações ambientais. Ceará: Imprensa Universitária, 2014.

OLIVEIRA, Leonardo Henrique de. Tratamento de água produzida contaminada com óleo diesel utilizando adsorventes funcionalizados. 2015. 225 f. Tese (Doutorado) - Curso de Engenharia Química, Universidade Federal de Santa Catarina, Florianópolis, 2015.

PERUZZO, Lucile Cecília. Influência de agendes auxiliares na adsorção de corantes de efluentes da indústria têxtil em colunas de leito fixo. 2003. 77 f. Dissertação - Curso de Engenharia Química, Engenharia Química e Engenharia de Alimentos, Universidade Federal de Santa Catarina, Florianópolis, 2003.

SCHONS, Elenice Maria. Desestabilização de emulsões visando a redução do teor de óleo em água. 2008.

UGARTE, José Fernandes de Oliveira; SAMPAIO, João Alves; FRANÇA, Silvia Cristina Alves. Rochas e Minerais Industriais [S.1.], p. 865-887, jan. 2008. 